\title{
Derecho Constitucional Hispanoamericano frente a la realidad institucional, manifiesta divergencia*
}

\author{
Jose Ignacio Humbarita" \\ Recibido: 5 de agosto de 2015 - Revisado: 25 de noviembre de 2015 \\ Aprobado: 30 de noviembre de 2015
}

\section{Resumen}

La clase política en el poder desde la independencia ha impedido la realización de principios y libertades esenciales a la democracia, muy a pesar de los esfuerzos de los verdaderos opositores (no de las derechas disfrazadas de opositoras cuando han perdido el poder) que han sido neutralizados por diferentes vías, haciendo inofensiva la consagración de algunos derechos fundamentales y la modernización de les estados nación de esta parte del mundo. De dónde surge que el verdadero reto jurídico, político y social se deba enfocar en tener en cuenta los intereses en disputa, en conciliar los mandatos constitucionales y legales con la realidad política de la región para que se convierta en generador del progreso. De suerte que a imagen de lo que ocurre en las democracias reales, las normas superiores sean el derecho viviente y se erijan en gestoras de progreso.

Luego de analizar la temática, se llegó a la conclusión de la existencia de una percepción negativa del poder político muy a pesar de la existencia y vigencia formal de democracias constitucionales debido a la incoherencia y desbordada ambición de los políticos, fenómeno que conduce inexorablemente al atraso en todos los campos y a las insalvables fisuras entre los diferentes sectores de la población en

"El presente artículo es producto del proyecto de investigación para optar al título de doctor en la UNED España - Doctorado en Fundamentos de Derecho Político. El título del citado proyecto de investigación es: Constitucionalismo hispanoamericano contradicho por la experiencia institucional

"'Magister en Derechos Humanos y Derecho Internacional Humanitario en la Universidad Sergio Arboleda (Bogotá). Docente de la Universidad Católica en Derecho Penal y Fiscal especializado Grupo para La Investigación Falsos Testigos. Correo electrónico: abogadoumbarila@yahoo.com 
la que minoría se encuentra integrada por las élites que direccionan a su servicio las instituciones, manipulación fácilmente evidenciable, y la mayoría conformada por los estratos que ocupan los lugares de depresión en las grandes urbes y en el sector rural, gran masa que desempeña únicamente el rol de gregaria en la actividad productiva y política de estos estados.

Palabras clave: derecho constitucional comparado, actividad política, clase política, instituciones, anacronismo, atraso, estratificación, inconformismo.

\title{
Latin-American Constitutional Law in the INSTITUTIONAL SITUATION EXPRESSES DIVERGENCE
}

\begin{abstract}
This the way the political class, entrenched in power since independence, has prevented the completion of principles and freedoms essential to democracy, in spite of the efforts of the real opponents (not to the right disguised of opposition, when they have lost power) which have been neutralized by different routes, making harmless the consecration of certain fundamental rights and modernizing of the nation states of this part of the world. It is here where the real legal, political and social challenge has to be focused on the not easy task taking into account the interests in dispute, to fulfill the constitutional and legal mandates with the political reality of the region so it could become a generator of progress. So we hope that luckily the image of what happens in the real democracies that the higher rules of living law will become a manager of the progress.

In this scenario is developed the current research, which examines the alternation of methods: empirical, theoretical, historical, inductive, deductive, analytical and comparative, used in order to support a conclusion that based on verifiable facts that allow submitting a constitutional and educational reengineering proposal.

To summarize, we conclude that there is a negative perception of the political power in spite of the existence of constitutional democracies due to the politics incoherence and overwhelmed ambition.

A phenomenon that leads inexorably to backwardness in all fields and unbridgeable gaps between the different sectors of the population, in which the minority
\end{abstract}


is composed by the elite, who routed to their service all the institutions, handling which is clearly identifiable; the most formed by the strata, who occupy sites in major depression of the big cities, and in rural areas. Big population, that plays only the role of gregarious in productive and political activity of these States.

Keywords: Comparative constitutional law, political activity, politicians, institutions, anachronism, backwardness, stratification, nonconformity.

\section{Direito Constitucional Hispano-americano frente à REALIDADE INSTITUCIONAL, MANIFESTA DIVERGÊNCIA}

\section{Resumo}

A classe política no poder desde a Independência tem impedido a realização de princípios e liberdades essenciais na democracia, apesar dos esforços dos verdadeiros opositores (não das direitas disfarçadas de opositoras quando tem perdido o poder) que tem sido neutralizados de diferentes maneiras, fazendo inofensiva a consagração de alguns direitos fundamentais e a modernização dos estados-nação de esta parte do mundo. Como surge que o verdadeiro desafio jurídico, político y social deve-se focar em levar em consideração os interesses em disputa, em conciliar os mandatos constitucionais e legais com a realidade política da região para que se transforme em gerador do progresso. Como exemplo do que acontece nas democracias reais, as normas superiores sejam o direito vivente e se erijam em gestoras de progresso.

Depois de analisar a temática, conclui-se a existência de uma percepção negativa do poder político apesar da presença e vigência formal de democracias constitucionais devido à incoerência e transbordada ambição dos políticos, fenômeno que leva de forma inexorável ao atraso em todos os campos e as insuperáveis fissuras entre os diferentes setores da população, na qual a minoria encontra-se formada pelas elites que direcionam ao seu serviço as instituições, manipulação facilmente evidenciável, e a maioria formada pelos níveis que ocupam os lugares de depressão nas grandes cidades e no setor rural, grande massa que desempenha unicamente um papel gregário na atividade produtiva y política de estes estados.

Palavras-chave: Direito Constitucional comparado, atividade política, classe política, instituições, anacronismo, atraso, estratificação, inconformidade. 


\section{Introducción}

El Derecho político en su contenido material, esto es el relacionado con las libertades políticas, instituciones y facultades deliberativas, profundizado por la férrea exclusión que hace una reducida clase política al monopolizar todas las instituciones estatales y regionales, impiden manifestaciones democráticas de los grupos opositores; manteniendo a los estados rezagados en el concierto internacional y a nivel interno en constante polarización por las marcadas diferencias sociales, hechos que contrastan con un sistema constitucional formalmente garantista.

Para visibilizar el anacronismo actual del sistema político presente en casi toda la región, se hace una breve reseña sobre el transcurrir de los derechos políticos y sistemas electorales desde el derecho poscolonial hasta el presente, con el fin de decantar que a pesar de la existencia de normas internas y múltiples instrumentos de derechos humanos sobre la materia, las maniobras políticas han cerrado el paso a cualquier intento de igualdad y de cambio de esas censurables costumbres políticas.

Esta tesis se refuerza en la coyuntura del tema político, económico, cultural, jurídico y de orden público y social que se proyecta en el incierto futuro de las naciones, muy a pesar del reconocimiento de Constituciones, después de experimentar, largos períodos dictatoriales durante los que se desconocieron los derechos fundamentales de la mayoría y el incrementó de la riqueza de las élites militar, clerical y política.

El ciudadano del común puede ver truncado su derecho a ser elegido en condiciones de igualdad o de acceder a cargos públicos, prerrogativas que en la cotidianidad le están vedados y asegurados monopolísticamente a los políticos. Dichas realidades se hacen patentes en las sociedades de este hemisferio donde se agudizan las condiciones de injusticia y desigualdad, denunciadas por la comunidad internacional, clamores que en gran número posteriormente se pierden en el olvido.

Demanda especial importancia este tema teniendo en cuenta la polarización de la política hispanoamericana que en la actualidad se debate entre gobiernos de derecha e izquierda, estos últimos resguardados en un pretendido socialismo del siglo XXI o neopopulismo, pero ambos con una nota coincidente al constituirse en nugatorios de los derechos políticos de los ciudadanos, que en el primer caso ven disminuidos sus derechos y libertades básicas a la vez que son víctimas de la violencia de estado; en el segundo, la pobreza y carencia de oportunidades que se matiza a través de subsidios que fomentan el atraso. 


\section{Aproximación al origen histórico del constitucionalismo e instituciones políticas}

Indicaremos brevemente a qué instituciones políticas corresponde el primer momento republicano de los estados ubicados al sur del Rio Grande: iniciaremos nuestro recorrido demostrando que al igual que la metrópoli de la que habían logrado su independencia, estos países permanecieron aferrados a esquemas conservadores que fusionaban en unidad indisoluble los intereses clericales con los seculares aunque dispuestos al cambio que promocionaba tanto la declaración de independencia norteamericana como los derechos del hombre y del ciudadano corolario de la Revolución Francesa, diferenciándose de España, en que esta fue renuente a reconocer el pluralismo político en su inicios, impenetrable al ideario de libertades, estado que para la época tenía como blasón: "los dos principios, el monárquico y el religioso, son los dos polos de la nación española. Las grandes ideas que pusieron en movimiento al pueblo español contra Napoleón: Religión, Patria y Rey" (Balmes, 1988, p. 79).

La independencia significó simplemente la separación de España, pero no cambio todas las circunstancias que desde tiempo atrás dividían la sociedad hispánica. La independencia no determinó la forma de gobierno que tendrían las nuevas naciones, y aunque no hubo desacuerdo sobre la necesidad de redactar constituciones, tales documentos podían tener objetivos diversos: unas facciones preferían la monarquía y otras la república (Rodríguez, 1975, p. 72).

Los nacientes Estados encontraron sustrato político y jurídico en la ideología liberal decimonónica imperante en Europa, sin embargo, el caos político del siglo XIX de la metrópoli se trasladó a esta región convirtiéndose en práctica, difiriendo únicamente en que el proceso independentista desencadenó la aparición de las primeras constituciones en estos estados con los fundamentos propios de la ilustración, cuadro que hizo exclamar a uno de los esclarecidos historiadores y políticos del siglo anterior de nuestro país acerca de la formación política en Hispanoamérica, lo siguiente: “(...) nació marcada con el pecado original de la revolución. Porque a diferencia de lo que ocurrió en Estados Unidos, nuestra independencia no fue un movimiento conservador y tradicionalista, sino esencialmente iconoclasta y revolucionario" (Gómez, 1958, p. 96).

Es posible afirmar sobre este primer momento político que estuvo imbuido por la inestabilidad propiciada por los fenómenos políticos, económicos y sociales 
dominantes para la época en toda Europa, fenómeno que aceleró la emancipación y formación de estas naciones y de otra parte, forjó el faccionalismo político característico en todo el subcontinente americano que aún se encuentra vigente.

\section{Formación de las instituciones democráticas e ideología política en la América hispana}

Las pautas resultantes de la antropología social que acreditan aspectos culturales, económicos, étnicos, sociales y políticos que les son comunes a todas estas naciones, características endógenas a las que se suman acontecimientos exógenos, como la crisis política vivida en la metrópoli propiciada por la ocupación napoleónica de su territorio, facilitaron la emancipación de las naciones hispanoamericanas, de donde nace la necesidad del enfoque comparado empleado en todo el recorrido de este trabajo.

Como punto de partida se tiene que el preludio independentista apenas se exteriorizó en la primera década del siglo XIX, el comienzo de la emancipación de la región se dio en Quito, Ecuador el 10 de agosto de 1809 y de allí se propagó a las demás naciones, movimiento liderado por los criollos contra los peninsulares que se concreta solo quince años después en todo el subcontinente hispanoamericano, con la conocida excepción del territorio cubano que únicamente alcanzó su "emancipación" hasta 1898 con la culminación de la Guerra cubano-hispano-estadounidense, fecha que marcó el fin del colonialismo español en la región; independencia que no significó un cambio en las instituciones e inequidad social, puesto que los que promovieron la autonomía de España únicamente buscaban conservar los privilegios que les proporcionaban las arcaicas instituciones, para su particular provecho, estado de cosas del que obtuvo beneficio la potencia americana que aprovechó esta coyuntura para fortalecer su carrera imperialista.

Las revoluciones hispanoamericanas tenían en sus ideales un cierto concepto de modernidad, constituido por dos anhelos: uno el de dejar atrás las formas de gobierno monárquicas para establecer la soberanía popular; y otro, el de alcanzar la liberación económica, mediante la derogatoria de las insoportables cargas coloniales que ahogaban la capacidad productiva de las gentes (Mejía, 2009, p. 48).

Como puede apreciarse de lo expuesto hasta este momento los estados recién independizados, enfrentaban una nueva lucha, la de constituirse en democráticos 
para alejarse de las formas autoritarias de gobierno, ¿pero a partir de cuándo se consolidan, si alguna vez ha ocurrido, las instituciones y el gobierno democrático en la región?

\subsection{Fase predemocrática}

Tras la independencia, las instituciones políticas, económicas y sociales de estas naciones son imitación de la metrópoli; en México (novohispanos) y en todos los demás países hispanos de América, imperó una tendencia entre lo monárquico y lo liberal; dicho de otro modo, el absolutismo morigerado por la influencia del liberalismo entronizado en la península y en los territorios de ultramar al revivir la constitución de Cádiz de 1812, "[N] os hemos acostumbrado a ver el monarquismo durante el período emancipador como una especie de patología política..., para los americanos del primer cuarto del siglo XIX, la monarquía era una creencia, mientras que la republica era una idea" (Breña, 2012, p. 48).

Posteriormente, ese ambiguo régimen caracterizado en México por propensiones imperialistas fue reemplazado en el período presidencial de Benito Juárez (18671872) durante el cual se definió la república mexicana que conoció su fin poco tiempo después con el advenimiento del porfiriato, período en el que se otorgaron las concesiones extranjeras que fortalecieron el dominio de las élites con el cual impusieron su autoritarismo y el consecuente empobrecimiento de los obreros y campesinos. En contraste, los otros estados de la región tendían hacia la consolidación republicana con el mantenimiento de instituciones arcaicas y destinadas a la estratificación social.

Esta reseña sirve para sintetizar que esa primera etapa política, para toda Hispanoamérica, se inclinó por el mantenimiento de la monarquía; para ese momento, las instituciones representativas no hacían parte del consciente colectivo de las sociedades de esta subregión y las demás instituciones respondían a ese antiguo modelo privilegiando a las clases dirigentes con exclusividad sobre las menos favorecidos, para quienes estaban vedados los cargos públicos de alguna relevancia, época en que otras instituciones de gran importancia, como las de educación, se encontraba en manos de la iglesia católica, consecuencia de esa yunta entre iglesia y Estado.

La anterior característica desembocará en el caciquismo que marcó aún más las desigualdades y quebrantamientos de los derechos básicos, consecuencia de la puja constante por el poder (tema que se retomará); circunstancia a la que se suman las 
disputas de las potencias europeas (Gran Bretaña y Francia) por ocupar el espacio de explotación económica que antes monopolizaba España, hasta que "la influencia estadounidense las fue desplazando, incluso por medio de invasiones armadas a los estados latinoamericanos" (Corpizo, J., 2009, p. 5).

La bandera estrellada no tardará en ondear sobre las torres de México, y de ahí seguirá hasta el Cabo de Hornos, cuyas olas agitadas son el único límite que el yanqui reconoce a su ambición (Preston, 2009).

También derivó como efecto reflejo, el clientelismo característico de la forma de hacer política, en la mayoría de naciones de la región se cimentó en las etapas tempranas poscoloniales para perpetuarse en el tiempo.

Los grandes terratenientes desarrollaron rápidamente el sistema del clientelismo electoral, de los votos cautivos o forzados, en sus feudos, para darle el carácter de "democracia” y legitimidad a sus campañas para convertirse en dueños de cada provincia y de cada país (Buenaventura, 1984, p. 41).

\section{2 ¿Etapa democrática?}

Por democracia se entiende actualmente la forma de organización política de la sociedad en cuya base se encuentra el respeto y protección de los derechos humanos, acorde con su definición, puntualmente debe considerarse implementada para los Estados de la América hispana, solo a partir del reconocimiento y concesión de derechos subjetivos de libertad e igualdad para todos, que se traduce según Tapia en el liberalismo como "ideología de reforma y experiencia de lo nuevo en la vida social e individual, en tanto se transitaba desde sociedades estamentales..." (Tapia, 2011, p. 18).

En reconocimiento a la anterior premisa, la instauración de la forma de gobierno democrática en la región solo se da finales del siglo XX, jalonada por las demandas de una población mejor capacitada y la inaplazable necesidad de armonizar las formas de Estado y de gobierno a las exigencias de los cambios promovidos por los instrumentos internacionales y regionales de derechos humanos y de Derecho Internacional Humanitario, como de la prevención dirigida a los gobernantes y en general a las autoridades con el proyecto radicado en las Naciones Unidas para la implementación por primera vez de un Tribunal Penal Internacional de carácter permanente. 


\subsubsection{Los 70, años convulsos}

Corresponde a una fase que duraría más de una década marcada por dictaduras militares en Centroamérica y el cono sur a mediados del siglo XX, patrocinadas por Estados Unidos de Norteamérica bajo la consigna macarthista en la que imperó la lógica de los autoritarismos militares con la negación de libertades y represión que reafirmó la vigente polarización de la sociedad, región en la que "[s]olo tres países (Colombia, Costa Rica y Venezuela)... contaban con gobiernos electos mediante comicios razonablemente libres y competitivos (Olguín, 2013).

Sin duda, constituyó una etapa vacilante en la historia republicana de las naciones hispanas de América del Sur, marcada por la dictadura militar bajo la égida de la conocida "operación cóndor", alianza entre la CIA norteamericana y las clases dominantes dictatoriales de esta parte del mundo, confabulación bajo la cual se avasalló de manera sistemática y criminal contra cualquier vestigio de oposición política, especialmente en Chile, Argentina, Uruguay, Paraguay y Bolivia, lugares donde la represión y crímenes como la desaparición forzada fueron utilizadas como política de estado de forma generalizada por los militares, cuyas atrocidades pueden consultarse en las diferentes Comisiones Históricas de la Verdad de cada uno de estos estados.

Mesoamérica y América meridional fueron convulsionadas por la desaparición y asesinato de líderes opositores a los regímenes militares que se fueron consolidando bajo el auspicio de Estados Unidos de Norteamérica.

\section{Sustrato y evolución de la clase política hispanoamericana}

La formación de bandos con pretensiones políticas en la región, desde México hasta la Patagonia (Argentina y Chile) estuvieron conformadas primigeniamente por movimientos libertarios influenciados por las proclamas de los revolucionarios franceses y de los ideólogos de la emancipación norteamericana confrontados con los opositores que mantuvieron su vocación conservadora que los aprisionaba a las viejas formas de gobierno absolutista de la metrópoli. Alcanzada la libertad, distintas facciones hicieron su aparición en el escenario político hispanoamericano, bandos nacidos de la pugna sobre la organización que más convenía a los nuevos 
estados, si se adoptaba la federalista del vecino del norte o se continuaba con la tradicional preponderantemente centralista.

A finales del siglo XVIII y pasada la mitad del siglo XX casi todo el Caribe fue dominado por tiranías que impusieron su impronta a través de negación de derechos civiles, persecución y exterminio de los opositores con el auspicio de la potencia vecina que de esta manera aseguró la expoliación de recursos naturales y riquezas de esta nuevas naciones, Salvador, Guatemala, Honduras, Haití, Nicaragua, Panamá tuvieron pues un signo trágico común que después se trasladaría a los pueblos suramericanos a lo que

\begin{abstract}
Washington tenía una explicación simple para todos sus problemas en la región ubicada en el sur del río Grande: los comunistas estaban abriendo un hueco en su patio trasero. Así pues, su respuesta consistió en colocar en el poder a aliados militares de confianza..., la Ley de Defensa Militar fue aprobada por el Congreso de Estados Unidos en 1951... Los ejércitos de esta área serian entrenados en la Escuela de las Américas. Según el plan Estados Unidos velaría por la defensa regional y global de Latinoamérica, mientras que los ejércitos locales se encargarían de las 'misiones nacionales', o sea, la contrainsurgencia dentro de cada país (Krehm, W., 1998, p. 31).
\end{abstract}

La guerra fría permitió a los Estados Unidos para sojuzgar a las naciones vecinas imponiendo y patrocinando dictaduras militares en la región, período en el que se hizo nugatorio cualquier derecho democrático, el poder se lo arrogaron dictadorzuelos militares que fueron retratados en grandes novelas políticas escritas por permios noveles latinoamericanos El señor presidente escrita por el guatemalteco Miguel Ángel Asturias, El otoño del Patriarca del colombiano Gabriel García Márquez La fiesta del chivo del peruano Mario Vargas Llosa y otros, la política de los derechos humanos fue desconocida en todo su aspecto sustancial, las condiciones de los pobladores se tornaron dramáticas su vida o muerte estaba a disposición del dictador y los opositores condenados al más vil crimen, la desaparición forzosa.

\title{
3. Desequilibrio institucional de la América española a partir del sistema legislativo y sus consecuencias
}

La primera y más visible consciencia se tiene en el índice de que el $90 \%$ aproximadamente de la renta de los estados Hispanoamericanos se distribuye entre 
solo un $5 \%$ de la población, porcentaje constituido por las élites, comportando la correspondiente explotación y exclusión de la mayoría, estado de cosas que no se logra sin permear a las autoridades públicas por medio de actos de corrupción, generando sistemas sociales convulsos, convirtiendo esta región en una de las más violentas del mundo, haciendo patente que "[E]1 sistema no es transparente, está dominado por las mismas élites políticas y económicas de siempre, corruptas, excluyentes ...Eso crea bloqueos y la gente abandona el sistema. Ahí está el brote de la violencia" (Revista Semana, 2013).

Formalmente, prima facie, las organizaciones en el actual estado democrático deberían encontrar su razón de ser en el principio constitucional del interés público, donde el vocablo institución simbólicamente sería el mecanismo estructurado por las sociedades que permite la interrelación social, en otras palabras, parafraseando al autor Mauricio Cárdenas, las normas jurídicas y culturales en su conjunto determinan la interacción social (Cárdenas, 2012).

Estados Unidos de Norteamérica y Canadá acopiaron de Gran Bretaña su tradición liberal, en contraste las nacientes naciones de la América española estuvieron signadas por privilegios e inequidad desde su emancipación.

Como resultado de todo lo anterior, en los Estados Unidos se instituyó un sistema político federal, de frenos y equilibrios (...) En contraste, en América Latina (México), durante el siglo XIX, la naturaleza intervencionista y generalmente arbitraria del medio institucional obligó a todas las empresas a operar de un modo altamente politizado, valiéndose de redes de parentesco, influencia política y prestigio familiar para tener acceso a los privilegios consagrados en las instituciones prevalecientes (Coatsworth 1978) (North, 1990).

Después de esta precisión sobre el término institución y su evolución en la región, puede extraerse la correlación existente entre la acción política y la actualidad de determinadas instituciones, esta correspondencia demuestra la incidencia que las prácticas políticas tienen sobre estos mecanismos de regulación social.

Decididamente, las "[i]nstituciones formales surgen de un proceso político" (Cárdenas, 1990 p. 101), si ese proceso político es deficiente, las instituciones y quienes las conforman estarán sellados por el distintivo de la ineficacia y corrupción; por consiguiente, las instituciones y el ejercicio político se encuentran en inescindible ecuación: a políticas públicas idóneas corresponde un modelo de bienestar y 
desarrollo; inversamente, a políticas públicas desacertadas, excluyentes y antiéticas concierne un modelo de inestabilidad institucional y subdesarrollo, panorama político e institucional presente en la gran mayoría de países de esta parte del planeta.

En este punto de la investigación parece incontrovertible que la visible incongruencia entre el constitucionalismo de esta latitud con la realidad política y por extensión de sus instituciones, frena su desarrollo. Paradójicamente, la mayoría de estos territorios cuentan con una gama de recursos naturales envidiable, pero estos son explotados irracionalmente. Actualmente como ha sido denunciado, los últimos gobiernos se han encargado de entregar a grandes multinacionales los recursos minerales para su explotación a cambio de una pequeña contraprestación para las naciones, hecho superlativo especialmente en Colombia donde se otorgan gabelas tributarias consistentes primordialmente en privilegios, dejando a cambio problemas ambientales que amenazan con terminar nuestras expectativas a un medio ambiente sano. Todo esto conduce a señalar que instituciones inocuas sumadas a una población que no cuenta con una formación elevada, permiten la vigencia de legislaciones ambiguas e instituciones extractivas.

Esta reflexión no es secundaria en esta línea argumentativa si se parte de la premisa de que la nación del norte fijó sus propias reglas inspirada en la evolución alcanzada por la ilustración inglesa en concreto y en general de la europea occidental, además, que su población no es resultado de la fusión de etnias como la hispanoamericana por los motivos expuestos, situación que le posibilitó organizarse internamente sin mayores contradicciones. Por el contrario, los nacionales de la subregión del continente no se fundaron bajo directrices propias de un convenio, fueron "organizados" por quienes se encontraban en el vórtice de la estructura social bajo condiciones similares a las impuestas por la metrópoli desde la época colonial, las reglas no se crearon en un procedimiento inclusivo, fueron dadas, tampoco se desarrolló un procedimiento para la búsqueda de instituciones justas como ocurrió en la nación del norte, coincidiendo con Acemoglu y Robinson solamente en el punto en el que el reparto del poder es restrictivo, las instituciones son absolutistas.

La circunstancia exógena de sometimiento de las naciones hispanoparlantes por parte de las potencias de turno, no es la visión restringida de autores contestatarios, por el contrario, es el reflejo objetivo y por lo tanto verificable de la enorme desigualdad entre estados poderosos y emergentes.

Este punto de inicio se convirtió en factor desencadenante de relaciones desiguales entre los estados hispanoamericanos con los países desarrollados y en 
particular con la potencia vecina cuyo gobierno pacta con los dirigentes de estos países sin discriminar sobre la manera de acceder al poder o su accionar en la vida pública e incluso personal, circunstancia que ha potenciado la presencia de dirigentes y clase política que no ha encontrado freno legal interno ni del sistema internacional que les impida hipotecar estas naciones para enriquecerse y sumirlas aún más en la dependencia con órganos como el Fondo Monetario Internacional, institución aparentemente plurilateral que en la practica desde su creación (julio de 1945) ha sido liderada exclusivamente por representantes de los países desarrollados, preponderantemente por los Estados Unidos atendiendo sus aportes en cuotas, imponiendo condiciones que afectan la inversión en políticas sociales en países subdesarrollados y planteando nuevos gravámenes que atentan con el escaso ingreso de la mayoría poblacional, el IVA por ejemplo.

Similarmente incide en esta dependencia el organismo de asistencia financiera de las naciones unidas, el Banco Mundial, que es regido por las potencias que lo han usufructuado para legitimar proyectos que atentan contra el ecosistema y que en el pasado reciente patrocinaron a los peores perpetradores de los derechos humanos (Pinochet en Chile, Videla en Argentina, Pacheco en Uruguay y Stroessner en Paraguay) en la región, además de imponer políticas económicas restrictivas a los estados deudores que conllevan desastrosos costos sociales que afectan a la clase más vulnerable de estos países.

Condiciones que impiden a esta población salir del atraso en busca de la prosperidad, situación a la que se suma las robustecidas fuerzas oscuras enquistadas en el poder de estos estados que impiden pensar en instituciones inclusivas y en el fortalecimiento y respeto de los derechos humanos, anomalía calificada por publicistas como estado dual:

[c]ategoría de "doble Estado" o "Estado dual", estos es, de la co-presencia de un nivel de doble poder: por un lado, un "estado normativo" (el estado de derecho, sometido al impero de la ley), y por el otro un "Estado discrecional", libre de actuar por fuera del principio de legalidad (...) (Bobbio, 2013).

Puede concluirse que las condiciones que determinaron la diferencia entre los estados ricos de norte y los pobres del sur, entre los que se encuentran los hispanoamericanos, radica en la forma en la cual se dio su nacimiento y la manera como se fueron estructurando institucionalmente, esto facilitó a los que se fundaron 
bajo el consenso subirse al tren de la industrialización y el bienestar y, a los que las condiciones les fueron impuestas inconsultamente, quedar relegados.

Por resultar ilustrativo para este debate, tal como sostiene la tesis de este artículo, el sistema legal en conjunto no garantiza per se la vigencia de los derechos fundamentales de todos los individuos en condiciones de igualdad, nos permitimos transcribir parte del artículo titulado "Dos formas de no hacer nada":

$[\mathrm{L}] \mathrm{a}$ otra forma de no resolver un problema profundo es exigir y lograr que su solución revista la categoría de una reforma de una reforma legal o, mejor constitucional. De esta forma, las nuevas normas consagran, como derechos del ciudadano, la paz, el fin del hambre, la pobreza, la enfermedad o la desnutrición. Se les atribuyen poderes mágicos a esos ejercicios constitucionales y legales, como si pudieran una vez decretados, transformar la realidad y lograr la redención de quienes sufren en este mundo.

El eslabón perdido, lo que hace falta para conectar los anuncios y los cambios constitucionales con la realidad de los ciudadanos, es la capacidad del Estado para realizar obras, proveer servicios y resolver los problemas de la gente (...).

La falta de gerencia en el sector público tiene numerosas raíces. La más importante es la injerencia de los políticos (...). Mientras que los cargos se sigan repartiendo sin consideración de las capacidades profesionales, los pomposos anuncios de los gobiernos y los cambios constitucionales y legales no pueden traducirse en la mejoría de la vida de la gente (Montenegro, 2014).

Indiscutible resulta el desequilibrio institucional de los estados del subcontinente derivado de los contenidos constitucionales que aparentemente promueven el derecho fundamental a la igualdad pero sustancialmente están diseñados para que los órganos políticos y públicos en general satisfagan la insaciable voracidad de las élites, basta mirar artículos tan importantes como el 125 de la carta colombiana según el cual bajo un aparente halo de moralidad, democracia, igualdad y transparencia, se permite el acceso de la función pública a través de concurso público para que los servidores sean de carrera, para tal fin existe un ente, empero, en las instituciones solo se ha promovido después de más de 23 años de su entrada en vigencia un número mínimo de concursos públicos y solo para cargos sin importancia, pues los de mayor remuneración y exigencia académicas están destinados para alimentar 
el clientelismo político y burocrático ${ }^{1}$, allí se ubican personas que ni siquiera han superado los respectivos concursos en la mayoría de los casos, las convocatorias se manipulan y dilatan en el tiempo para permitir todo el tráfico de influencias y se requiere recurrir a acciones de tutela para que finalmente se cumplan. Lo que hace más grave y legitimo ese escenario es la cláusula contenida en la norma mencionada, según la cual "se exceptúan los de libre nombramiento y remoción", pues esta que es una excepción permite que las vacantes y nuevos cargos se sigan repartiendo burocráticamente, constituyéndose en la regla respecto a derechos de acceso a cargos públicos, la excepción, son las oportunidades de acceso en igualdad de condición.

Las maniobras legislativas y administrativas igualmente inciden negativamente en las políticas públicas de desarrollo...

Hace mucho que los economistas han señalado los bajos niveles de recaudación impositiva en Latinoamérica, Lo han atribuido, e general, al trato preferencial que ha obtenido empresarios cortesanos amigos del gobierno, a la evasión impositiva generalizada (basada en la idea de que "para qué pagar impuestos, si igual se los van a robar funcionarios corruptos (...) (Oppenheimer, 2012, p.147).

Con estas maniobras originadas desde el Congreso se perpetúa la ineficiencia de la administración y de los organismos que la conforman.

\section{Respuesta ciudadana}

El culto a la ilegalidad y el desinterés por lo político son dos respuestas de la ciudadanía. Sociedades desorganizadas son sin duda caldo de cultivo de violencia y de atraso, si el presupuesto para contar con instituciones justas e inclusivas, es

\footnotetext{
${ }^{1}$ Artículo 125. Los empleos en los órganos y entidades del Estado son de carrera. Se exceptúan los de elección popular, los de libre nombramiento y remoción, los de trabajadores oficiales y los demás que determine la ley. Los funcionarios, cuyo sistema de nombramiento no haya sido determinado por la Constitución o la ley, serán nombrados por concurso público. El ingreso a los cargos de carrera y el ascenso en los mismos, se harán previo cumplimiento de los requisitos y condiciones que fije la ley para determinar los méritos y calidades de los aspirantes (énfasis no es del texto).

El retiro se hará: por calificación no satisfactoria en el desempeño del empleo; por violación del régimen disciplinario y por las demás causales previstas en la Constitución o la ley.

En ningún caso la filiación política de los ciudadanos podrá determinar su nombramiento para un empleo de carrera, su ascenso o remoción.
} 
el haber alcanzado por lo menos una sociedad ordenada, estos países tendrán que trabajar arduamente por medio de una reconfiguración del proceso democrático que sirva de canal para el rediseño de las instituciones donde los ciudadanos se sientan libres e iguales (para referirnos solo a dos generaciones de derechos humanos) y puedan al fin confiar en sus instituciones.

Es axiológico que solo desde la premisa de una sociedad organizada, "los ciudadanos tienen, normalmente, un sentido efectivo de la justicia, y por ello cumplen generalmente las reglas de sus instituciones básicas, a las que consideran justas" (Rawls, 1996, p. 56), en sociedades convulsas como las hispanoparlantes del continente, la cultura de la ilegalidad hace carrera, se rinde culto y se sitúa en un mismo nicho a criminales protervos y a políticos desdeñables.

\section{Ambigüedad legislativa y su influencia sobre el modelo económico de estos estados}

El barómetro actual de Hispanoamérica a nivel institucional marca un aparente periodo de "crecimiento económico" y calma. Crisis y desestabilización en Venezuela, Cuba y Nicaragua, y de transformación en Ecuador que bajo el mandato de Rafal Correa, también de ideología socialista, durante más de siete años y con posibilidad de ser reelegido nuevamente por la popularidad alcanzada gracias a los avances en educación e infraestructura que han modificado la forma de gobernar en ese estado que tuvo siete presidentes en solo trece años ${ }^{2}$, éxito que radica en parte en el control estatal ejercido para erradicar la evasión que ha permitido triplicar el recaudo tributario.

Pero el coeficiente de Gini muestra la enorme brecha entre ricos y pobres en estos estados y todas las trabas históricas que impiden superarla, indicadores que evidencian las consecuencias de esa inequidad: incidencia en el atraso característico de los países de la América hispana, corrupción en todos los niveles públicos que incluso permean el sector privado, factores que constituyen una insalvable talanquera que impide avanzar en las políticas públicas, anomalía que se convierte

${ }^{2}$ Abdalá Bucaram (1996-1997); Fabián Alarcón (1997-1998);Jamil Mahuad (1998-2000); Gustavo Noboa (2000-2003); Lucio Gutiérrez 2003-2005); Alfredo Palacio (2005-2007); (Rafael Correa enero 2007 a la fecha). 
“[e]n una traba al crecimiento económico futuro. La inequidad también potencia la inconformidad social, haciendo más difícil la búsqueda de la estabilidad política y, en consecuencia, deteriorando la tranquilidad y la capacidad de generar consensos que requieren los grandes debates y las grandes decisiones de política pública” (Carrasquilla, 2014, p. 20).

Las demandas de gremios y asociaciones no tienen más que una promesa inmediata por parte de los gobiernos, promesas incumplidas pues no hay políticas sostenidas ni compromisos para alcanzar un desarrollo planificado. Interesante debate ha ocasionado en el mundo académico la reciente publicación del economista francés Thomas Piketty del libro "El Capital del Siglo XXI" en el que propone una tesis sencilla sobre la manera de interrumpir el aumento de los índices de desigualdad: gravando la riqueza, argumento rebatido por quienes se ven afectados como Bill Gates que en cambio quien ve una fórmula en el impuesto al consumo, sin lugar a dudas esta receta ha sido aplicada en el territorio hispanoamericano de manera indiscriminada provocando más desigualdad porque se gravan los artículos que son de obligatorio consumo (bienes esenciales) a la par que se eximen de renta a los grandes capitales.

\section{Interferencia de la institución religiosa en la institucionalidad política}

A pesar de que una de las grandes empresas liberales ha consistido en la escisión del estado de la iglesia, es evidente que el laicismo de estos estados es solo relativo y, lo que es peor, con la entrada en vigencia del neoconstitucionalismo, los estados hispanoamericanos han devenido en más confesionales en virtud del pluralismo teológico.

Grave crisis está conllevando en la esfera de lo público la creación y aceptación como por arte de magia de múltiples credos e instituciones religiosas y pseudo religiosas, promovidas por la reforma constitucional de los 80 en las naciones de la América hispana, autonomía de cultos y credos atentatorios de las libertades de elección de los individuos sin entrar a analizar las exenciones a pesar de la manera, muchas veces manipulada, que aseguran el diezmo que enriquece a pastores y arruina a los feligreses ante la mirada indiferente de las autoridades y órganos de control, 
fenómeno de expansión de las religiones y su conformación en instituciones, que se explica, en parte, por la evolución de los derechos humanos y la consideración de la libertad de escoger religión como un verdadero derecho fundamental, consideración de la que "se advierte en los textos legislativos una eclosión de la tutela del hecho religioso (...)” (Navarro-Valls, y Palomino, 2000, p. 318).

Gobierno e iglesia, dos establecimientos que vienen interactuando desde el nacimiento mismo de las naciones del subcontinente atenuando cada más sus fronteras ideológicas para coincidir en su finalidad última, el poder.

Culturalmente los primeros momentos de estas naciones se caracterizaron por la hegemonía de la religión católica impuesta por la Corona, hecho religioso que las marcó similarmente. La cosmogonía de sus habitantes fue deformada, desde entonces yacieron dispuestos a aceptar la culpa por sus acciones contra la imposición moral y enseñanzas religiosas y por supuesto la sumisión ante el más fuerte.

E1 reconocimiento pluralista comportó que las diferentes confesiones trascendieran el espacio de lo privado, o en términos althusserianos, se transformaran en aparatos ideológicos del estado (Althusser, 1969).

Esta tendencia ha sido aprovechada hábilmente por la clase política de la región que para alcanzar sus objetivos establece alianzas con jerarcas de la iglesia católica o con pastores de otras religiones e incluso sectas que les aseguran su elección y de paso les garantizan "súbditos dóciles y manejables, a fin de poder dominar sin contradicción” (Navarro-Valls, y Palomino, 2000, p. 316).

La protección judicial a nivel interno e internacional de la tolerancia religiosa, es consecuencia lógica de la preponderancia de los derechos humanos en la vida social, jurídica y política de los Estados democráticos, paradójicamente sus nocivos efectos no se pueden ocultar, fenómeno que amenaza por igual a Estados Unidos, a Europa y con mayor razón a estas naciones con una arcaica formación académica que las hace fácil presa de lo que "Paul Tilich llama "cuasi religiones" y, correlativamente, a incidir en parecidos mayores excesos que las religiones tradicionales" (Tilich, P., citado por Navarro-Valls, y Palomino, 2000, p. 324).

Circunstancia cultural que cierne sobre estas naciones un peligro inminente representado en la configuración de partidos políticos denominados centro y social demócratas que han transmutado las expectativas sociales en ocultos totalitarismos, teocracia e ideología, los intereses de las iglesias son inconexos con los del estado, razonamiento que dio lugar a que movimientos liberales provocaran el rompimiento del contubernio estado-iglesia hasta alcanzar los estados seculares que privaron 
al poder eclesiástico de beneficios, prebendas, bienes, exenciones y sobre todo de facultades que eran verdaderas intromisiones en la esfera pública y que impedían el avance hacia la modernidad y la tolerancia.

Cabe recordar, que en Colombia y Ecuador al igual que México fueron los liberales radicales quienes impulsaron estas medidas, incluso la expulsión de los Jesuitas. Ese movimiento político colombiano en 1863 dio inicio a una serie de disposiciones tendientes a desentrañar la economía de las arcaicas instituciones y del modelo colonial, sin embargo, los conservadores, integrados por las élites y el clero, pugnando por el mantenimiento del statu quo, se integraron con otros estamentos en un movimiento denominado "regeneración" que resucitó el binomio estado-iglesia católica en el primer plano del poder. En Colombia, con la entrada en vigencia de la Constitución de 1991 y en México con la reforma de 1992, se abrió un nuevo espectro en la relación estado-iglesias con las consecuencias relacionadas.

\section{8. ¿El deber ser que imponen las normas convencionales, forma parte de la institucionalidad hispanoamericana?}

El concepto de isonomía dio origen a la democracia entendida como la mejor forma de gobierno en la Grecia clásica en contraposición a la tiranía, a la vez que es la idea que da contenido al principio democrático que conlleva a la igualdad política y civil de los ciudadanos.

Contemporáneamente, del principio democrático deviene la carga de los ciudadanos de participar en la vida política, cívica y comunitaria del país; además de facultarlos para participar en la conformación, ejercicio y control del poder político, control que se ejerce a través del instrumento constitucional y legal del voto programático "según el cual el programa propuesto por un candidato se vuelve obligatorio y vinculante una vez sea elegido. Por lo mismo, existe un hito inescindible entre el voto, la soberanía popular y la revocatoria de mandato..." (Corte Constitucional colombiana Sentencia T-263, 2010).

Desafortunadamente, la materialización de este principio solo tiene presencia, empleando términos rawlsianos, en sociedades organizadas, en las que beneficios y obligaciones se reparten equitativamente, valga decir, de aquellas que se construyen sobre instituciones justas y esa como lo hemos venido señalando no es una característica de las hispanoamericanas que corresponden con todo a las de una democracia disfrazada. 
Solamente el sistema regional de derechos humanos en circunstancias extremas acude a servir de sustituto ante las maniobras de todo el entramado legislativo de los estados de la América hispana que potencia a quienes detentan el poder para neutralizar cualquier demanda democrática, pero sus decisiones solo constituyen una sanción contra el estado y no contra los perpetradores que casi siempre continúan su accionar amparados en la impunidad.

El deber ser, que es la satisfacción de interés colectivo por medio del ajuste de todo el ordenamiento jurídico a los valores, principios y derechos fundamentales consagrados en las constituciones se torna etéreo en este entramado político legislativo, es decir tiene vigencia, más no eficacia.

\section{Control constitucional mecanismo insuficiente para vigilar la producción legislativa}

Cuando el constitucionalismo abusivo referido al uso despótico de los mecanismos de enmienda de la carta por quienes pretendieron y pretenden perpetuarse en el poder (Chávez, Ortega en Nicaragua, Morales en Bolivia y Uribe en Colombia) atropellando la oposición "[y] eliminar los controles políticos... ejecutivos con control sobre el legislativo han deformado con éxito de forma paulatina la Constitución, para constitucionalizar sus aspiraciones de gobierno" (Bernal, 2014, p. 22), ha surgido una respuesta democrática constitucional encaminada a corregir ese estado de cosas inconstitucionales, por vía de ejemplo, la justicia constitucional colombiana frenó la reelección por segunda vez de Uribe Vélez en el año 2010 (Corte Constitucional, Sentencia C-14, 2010).

El punto de arranque de la ola democrática constitucional para la subregión se dio con posterioridad de la mutación del estado español de dictadura en social y democrático de Derecho (Constitución española, Art. $1^{\circ}$., ordinal $1^{\circ}$.), en 1978, producto de la transformación en la eurozona y en general del mundo entero, pero esencialmente debido al cambio de la sociedad española, factores que abrogaron el régimen dictatorial para dar paso nuevamente a la democracia.

La Constitución Ibérica de 1978 inspirada en la Ley Fundamental de la República Federal de Alemania (1948) transmitió su influjo a los textos superiores hispanoamericanos a finales del siglo anterior. Todos estos textos convergen en un tópico: la consagración de la supremacía de la norma constitucional en el contexto 
del ordenamiento jurídico, disposición que motiva la implementación de un órgano encargado de su salvaguardia y otros mecanismos.

No en vano a pesar de que su surgimiento se diera en etapa temprana del siglo XIX en Norteamérica y posteriormente en 1920 en Europa occidental con Hans Kelsen, la justicia constitucional ha alcanzado los mayores niveles de desarrollo paralelamente con el derecho procesal constitucional en la América española debido a la continua conculcación de los derechos esenciales de los pobladores, avance que ha sido considerado como "(...) una posición científica de dimensión sustantiva, para referirse a la nueva parcela del Derecho público que se encarga del estudio sistemático de la garantías constitucionales y de la magistratura que las conoce" (Ferrer, 2013, p. 61).

No obstante, la refundación de los países hispanoparlantes en estados constitucionales liberales a partir de una constitución de la que dimana la unidad política así como la elaboración y mantenimiento del orden jurídico, no resulta suficiente barrera para evitar las contumelias y corrupción que enerva la cimiente sobre la que se levanta la estructura de estos estados.

Por consiguiente, la consagración de derechos humanos, instituciones y mecanismos de protección son burlados por quienes están obligados a respetarlos, mírese en punto de esta reflexión el caso colombiano, en el que todo el sistema electoral es un régimen de burlas, en el momento en que se escriben estas líneas, solamente en los últimos ocho años, hay cerca de sesenta políticos condenados por alianzas con los paramilitares, que al quedar inhabilitados han legado a sus familiares quienes en la actualidad usufructúan todo ese poder y espuria influencia.

En otras palabras, ese signo distintivo de los estados constitucionales que los configura en un régimen de separación y equilibrio de poderes, nivelado por “(...) frenos y contrapesos -un sistema que comúnmente incluye una legislación bicameral, veto del poder ejecutivo, y un poder judicial encargado de preservar la supremacía de la Constitución" (Gargarella, 2012), solo es una formalidad, la praxis nos muestra sin lugar a equívocos que el mismo poder constituyente legisló para favorecer a esa controvertida clase política y si con esto no bastara, cuando encuentran algún impedimento legal a su ambición, han apelado desaprensivamente a las enmiendas de la Carta Política, con la finalidad de obtener provecho para sí o para sus prosélitos.

A fortiori, la manera como se encuentran regladas constitucional y legalmente las campañas políticas y la elección en estos países, les permite a los políticos mantener un control absoluto, agregándole a lo anterior, que quienes presiden los 
llamados organismos de control y vigilancia (Contraloría General de la República y Ministerio Público) ejercen un gran poder y despliegan el control fiscal, son elegidos de manera conveniente por los políticos y magistrados de la rama judicial, de tal suerte que actúan solamente para acallar a los opositores de los partidos más fuertes, allanando el camino para que pueda el partido político dominante maniobrar libremente muchas veces contra los intereses de toda la nación, a la vez que agigantan de manera inconveniente la burocracia estatal y con ella el inusitado gasto presupuestal encadenado por un verdadero tráfico de influencias.

Un aspecto plausible del sistema judicial constitucional mixto característico de todos los países hispanoamericanos (caso colombiano, venezolano ${ }^{3}$, mexicano, boliviano y en general todos los países de la América hispánica), consiste en haber impedido algunos embates dirigidos a sustituir la constitución. En cuanto a la legitimidad y oportunidad para interponer la acción de constitucionalidad o recurso de inconstitucionalidad español ${ }^{4}$, observamos semejanza en cuanto al origen $^{5} \mathrm{y}$ teleología ${ }^{6}$, con algunas particularidades atendiendo al contexto político y estructura del Estado.

3 Artículo 334 Todos los jueces o juezas de la República, en el ámbito de sus competencias y conforme a lo previsto en esta Constitución y en la ley, están en la obligación de asegurar la integridad de esta Constitución.

En caso de incompatibilidad entre esta Constitución y una ley u otra norma jurídica, se aplicarán las disposiciones constitucionales, correspondiendo a los tribunales en cualquier causa, aún de oficio, decidir lo conducente.

Corresponde exclusivamente a la Sala Constitucional del Tribunal Supremo de Justicia como jurisdicción constitucional, declarar la nulidad de las leyes y demás actos de los órganos que ejercen el Poder Público dictados en ejecución directa e inmediata de la Constitución o que tengan rango de ley, cuando colidan con aquella.

${ }^{4}$ Constitución española, artículo 161, numeral primero, literal a) Del recurso de inconstitucionalidad contra leyes y disposiciones normativas con fuerza de ley. La declaración de inconstitucionalidad de una norma jurídica con rango de ley, interpretada por la jurisprudencia, afectará a ésta, si bien la sentencia o sentencias recaídas no perderán el valor de cosa juzgada.

${ }^{5}$ Propuesta de Hans Kelsen inicialmente para la Constitución alemana de 1919 y posteriormente la austriaca

${ }^{6}$ Amparo del Texto supremo contra ataques y violaciones de las actuaciones de los poderes públicos en especial del legislativo.

\section{Artículo 163}

Cuando un órgano judicial considere, en algún proceso, que una norma con rango de ley, aplicable al caso, de cuya validez dependa el fallo, pueda ser contraria a la Constitución, planteará la cuestión ante el Tribunal Constitucional en los supuestos, en la forma y con los efectos que establezca la ley, que en ningún caso serán suspensivos. 
Con todo, el sistema de control constitucional hispanoamericano, tutela judicial propiamente dicha de la Carta Política que solamente se dio a partir de la modernización de esos textos superiores, incluyendo un procedimiento más exigente para su reforma (rigidez constitucional) que el procedimiento legislativo ordinario e implementando un auténtico órgano encargado de resguardar su supremacía consonante con el modelo kelseniano, todavía resulta insuficiente a la hora de contener la ambición de los políticos de la región. Incluso así debe reconocerse, que a pesar de la desaprobación de tratadistas conservadores, la jurisdicción constitucional ha paliado el déficit en el tema de políticas públicas de los órganos competentes en renglones como salud, hacinamientos carcelarios, desplazamiento poblacional, pago oportuno de salarios y pensiones a los distintos gremios, además de erigirse como guardián supremo de la constitución y enmendar actos administrativos antidemocráticos.

En Colombia, la Corte Constitucional ha emitido una serie de decisiones que han permitido contextualizar los derechos fundamentales de los colombianos en el marco del estado social ante el desgreño e incuria del administrativo y del legislativo yuxtapuesta a la ineptitud y venalidad de muchos jueces. A pesar de la fuerte oposición de los sectores conservadores que critican el amplio espacio en las políticas públicas ganado por la jurisdicción constitucional, esta ha reemplazado en algunas materias públicas la reconocida incuria de quienes están obligados constitucionalmente a garantizarlas.

\section{Transición institucional contemporánea en la región}

A pesar del cambio de paradigma constitucional ocurrido en los años 80 en esta parte del mundo no mutó la práctica política, por el contrario, los políticos con muy contadas excepciones (Chile) vieron fortalecido su accionar. En México, la coyuntura que significó la pérdida de la hegemonía del PRI (Partido Revolucionario Institucional) en la presidencia de la república que abarcó de 1929 al 2000 y la llegada al poder de un representante del partido opositor PAN (Partido de Acción Nacional), generó inestabilidad institucional.

En Colombia, desde finales de los 70 se vivió un oscuro período en el que el narcotráfico liderado por los grandes carteles de Medellín y Cali con Pablo Escobar y los hermanos Orejuela Rodríguez a la cabeza respectivamente, permearon casi todas las instituciones públicas y privadas, sembrando terror en la población con sonados atentados terroristas hasta 1993 cuando fue dado de baja el capo Pablo 
Escobar Gaviria en un enfrentamiento con las autoridades asesoradas por la DEA y más tarde con la extradición de los hermanos Orejuela hacia los Estados Unidos.

Los miembros de estos carteles ante la interdicción marítima y aérea desplegada por la DEA se aliaron con narcotraficantes mexicanos quienes asumieron el control explotando más de 1592 kilómetros de frontera con el país del norte para burlar el control de las autoridades estadounidenses, delincuentes que se han desplazado y asociado con sus homólogos guatemaltecos, convirtiendo al país centroamericano en un corredor estratégico. Estas alianzas han creado en la región verdaderas estructuras criminales transnacionales.

El narcotráfico se presenta como un factor desestabilizador de las instituciones de estos países, parafraseando a Garay las instituciones en Colombia, Guatemala y México se reconfiguraron (Garay, y Salcedo-Albarán, 2010) como consecuencia del anacronismo institucional y corrupción de quienes las representan.

La falta de sincronía entre lo legislado y la dinámica institucional de los estados hispanos de esta parte del mundo, se mide igualmente por la abrumadora concentración de la riqueza en pocas familias, este es lugar común de una economía casi feudal, donde unos pocos se han apropiado y se siguen apropiando de todo gracias a su cercanía con el poder y a manipular las leyes al ritmo de sus intereses; Colombia y México, por vía de ejemplo, guardan una perceptible identidad, en cada uno de estos países son las familias políticas las propietarias de bienes y las que perciben la mayor cuota de la renta y por supuesto sus allegados, en México a pesar de la vecindad con Estados Unidos y Canadá, son inevitables los oligopolios en los renglones más productivos de la encomia (envases, telecomunicaciones y cemento entre otros), "México ha generado..., una profunda desigualdad con escaso crecimiento, de hecho, lo afianzado del poder y de la riqueza de su élite supone un enorme obstáculo para el crecimiento del país"(Sharma, 2010).

Este panorama se presenta igualmente debido a los mecanismos diseñados para ejercer el derecho a elegir y ser elegido y para acceder a cargos públicos, cerrando las aspiraciones de la mayoría, Chile post dictadura, constituye la excepción en la región de ahí su reconocido auge económico y desarrollo en instituciones de la ciencia y educación, pues en los dos gobiernos de izquierda de Michelle Bachelet (2006-2010 y 2014) se ha tenido en cuenta la meritocracia tanto así que se ha afirmado que “(...) probablemente sea el gabinete más globalizado de América Latina” (Oppenheimer, 2012 p. 17), los demás solo son el reflejo de una institucionalidad cerrada a cualquier expectativa democrática y condicionada a los intereses de la élite. 


\section{Conclusión}

No cabe duda que la posibilidad de elección de instituciones mediante un procedimiento llevado a cabo por consenso "constituye un elemento central en cualquier descripción plausible de la justicia” (Sen, A., 2012, p. 112), tal como lo idealizó Rawls, pero esto de manera limitada solo se ha presentado en los países del hemisferio norte, en el subcontinente han sido impuestas y son controladas por las élites.

De tal suerte que quienes ejercen el poder político en la región tienen la potestad "[d]e establecer instituciones económicas para enriquecerse y aumentar el poder a costa de la sociedad" (Acemoglu, y Robinson2013, p. 102), el ordenamiento jurídico que crea las reglas de comportamiento del individuo en la sociedad, sospechosamente, ha servido y servirá para la defenestración de los derechos de la mayoría en manos de la minoría, siga encarnada en la élite, en palabras autorizadas, "[s] iempre estamos atrapados en relaciones de fuerza y obediencia ante las exigencias de poder, y a su vez ambas están agregadas y disfrazadas en formas jurídicas, tal como lo argumentara Foucault decididamente" (Douzinas, 2010, p. 9).

Los fenómenos intrínsecos y extrínsecos expuestos en precedencia han impedido la concreción del sueño bolivariano, de Artigas, de Morazán, de San Martín de una hispanoamericana unida, congregada como si fuera una sola nación, integrada en el principio democrático de soberanía nacional y en el bienestar común, para finalizar realizando uno solo, el de la oligarquía.

Todas estas antípodas hacen parte de la arquitectura de los estados-nación hispanoamericanos, tornándola incoherente con lo que enseña su historia, con lo ofertado por sus riquezas materiales y la valiosa aportación de su población, además de truncar la aspiración de progreso. Tema palpitante y de actualidad que induce a demandar la necesidad de reexaminar las normas que disciplinan el ejercicio político para evitar su manipulación a través de una reingeniería constitucional, el reto posterior, consistirá en fomentar una política pública que actualice el modelo educativo haciendo énfasis en la eticidad que debe preceder cualquier actividad política de los candidatos y de los electores, puesto que no es posible la concesión de derechos subjetivos sin el conocimiento de deberes, se debe educar a la mayoría para que esté en condiciones idóneas de elegir a la minoría que asume la representación de sus intereses, en otras palabras, parafraseando a Nicanor Parra, el primer deber humano es el de respetar los derechos humanos. 
En el mismo orden de ideas, se hace impensable que pueda sugerirse un cambio en la 'cultura' política, si este no cuenta con el apoyo de la comunidad internacional, mírese como estos gobernantes (caudillos, dictadores, plutócratas, demócratas y otros) gozan de total impunidad a pesar de lo manifiesto de sus tropelías por cuanto cuentan con la aquiescencia de las potencias a las que les permitieron el saqueo de riquezas o el uso militar de su territorio durante su mandato, además, de encontrarse amparados porque el producto de su insaciable latrocinio, ha sido sistemáticamente depositado en los llamados paraísos fiscales.

Precisamente el inconformismo y denuncias de los ciudadanos de la región sobre la conducta de los políticos ha alcanzado la opinión pública y estrados de justicia internacionales producto de una ciudadanía mejor formada, los ciudadanos de ahora gozan de una mejor información y preparación que los que habitaban la América recién independizada de la metrópolis, sin embargo, es inocultable que el interés de los gobernantes en materia de educación no ocupa en el ranking de prioridades un lugar destacado, pues las mayores partidas del presupuesto se destinan para mantener un, cada vez más, exagerado aparato burocrático, fuerza pública y organismos de seguridad que faciliten su continuidad sin contratiempos.

De tal suerte, que el énfasis que se le dé a la educación permitirá paralelamente formar en un contexto de actualidad a ciudadanos para que cumplan con sus deberes y obligaciones entre ellas la de elegir idóneamente sin presiones y su voto llegue a ser de opinión, como también la de acceder en igualdad de condiciones a cargos de la administración pública bajo claras reglas que atiendan únicamente cualidades y no privilegios, todo ello incidirá en la obtención de seguridad, bienestar para la mayoría y en el desarrollo de las naciones hispanas del continente.

\section{Referencias}

Acemoglu, D. y Robinson, J. (2013). "Por qué fracasan los países”, Bogotá, Planeta, (5a reimpresión, traducido por Marta García Madera), p. 102.

Althusser, L. (1969). "Ideología y aparatos ideológicos de estado”.

Barnechea, A. (2011). "Perú, país de metal y de melancolía”, México, Fondo de Cultura Económica.

Balmes, J. (1988). “Política y Constitución”, Madrid, Centro de Estudios Constitucionales, p.79.

Bernal, P. C. (2014). Ámbito Jurídico, Bogotá, Legis, p.22 
Bobbio, N. (2013). "Democracia y secreto", México, Fondo de cultura económica, traducción Artella Aureli y José Fernández Santillán

Breña, R. (2012). "Las independencias hispanoamericanas y la revolución liberal española”, Madrid, Marcial Pons. p. 137

Buenaventura, N. (1984). “Clases y partidos en Colombia”, Bogotá, CEIS. p. 41

Cárdenas, M. (2012) “Introducción a la economía colombiana”, Bogotá, Alfaomega, p. 100

Carpizo, J. (2009). “Concepto de democracia y sistema de gobierno en América Latina”, Bogotá, Universidad Externado. p. 5.

Carrasquilla, A. (2014). Equidad social: tres tristes trabas, Revista Dinero, Bogotá, p. 20.

Constitución Política de 1832, art. 11

Corte Constitucional de Colombia, Sentencia C-141 de 2010.

Corte Constitucional de Colombia, Sentencia T-263 de 2010, Magistrado Ponente: Juan Carlos Henao.

Constitución española, artículo $1^{\circ}$, ordinal $1^{\circ}$.

Constitución española, artículo 161, numeral primero, literal a

Corte Interamericana de Derechos Humanos, Caso: Manuel Cepeda Vargas vs Colombia, Sentencia del 26 de mayo de 2010.

Corte Suprema de Justicia, Sala Penal, única instancia 34653, 27 de septiembre de 2010.

Douzinas, C. (2008). "El fin de los derechos humanos”, Bogotá, Legis, p. 9.

Eastman, J. M. (1982). Perfiles políticos”, Bogotá, Plaza y Janes.

Ferrer, Mc. G. E. (2013). "Panorámica del Derecho procesal constitucional y convencional”, Madrid, Marcial Pons.

Garay, S. L. y Salcedo-Albarán, E., (2014). “Narcotráfico, corrupción y Estados”, Bogotá.

Gómez, H. Á. (1958). “La revolución en América”, Bogotá, Segundo festival del libro colombiano.

Henao, J.C. (2013) “El ideario de la constitución de 1863 no ha muerto”, Diario El Tiempo.

Krehm, W. (1998). “Democracias y tiranías del Caribe”, Bogotá, Planeta, p. 31.

Leguizamón, H. C. (2013). Revista Semana. América Latina-Las venas abiertas, p. 98.

Mejía, V. A. (2009). "El destino trágico de Venezuela”, Bogotá, Tierra Firme. p. 48.

Montenegro, A. (2014). "Dos formas de no hacer nada”, artículo publicado en Ámbito Jurídico, Bogotá.

Navarro-Valls, R. y Palomino, R. (2000). “Estado y Religión”, Barcelona, Ariel, p. 318

North, D. C. (1990). "Institutions, Institutional Change and Economic Perfomance, Cambridge Univ. Press.

Olguín, U. F. “Los partidos políticos en América Latina: evolución de su marco jurídico”. Recupeado de http://revistadigital.sre.gob.mx/images/stories/numeros/n79-80/olguin.pdf 
Oppenheimer, A. (2010). "Los Estados Desunidos de Latinoamérica”, Madrid, Algaba Ospina, W. (2012). "Dónde está la franja amarilla”, Bogotá, Mondadori.

Preston, discurso en 1836 ante el senado de ese país, citado en: Carpizo J. 2009.

Rawls, J. (1995). “Teoría de la Justicia”, México, (2ª edición).

Rawls, J. (1996). "Liberalismo político", México, Fondo de Cultura Económico, (1ª reimpresión).

Rodríguez., J., E., (1975). "El nacimiento de Hispanoamérica: Vicente Rocafuerte y el hispanoamericanismo, 1808-1832”, Fondo de Cultura Económica, México. p. 72.

Sen, A. (2012). "La idea de la justicia”, Bogotá, Taurus, 6ª reimpresión, traducción de Hernando Valencia Villa, p. 112.

Sharma, R. (2013). "Países emergentes en busca del milagro económico", Bogotá, Aguilar, trad.: Laura Vidal, p. 103

Tapia, L. (2011). "Política Salvaje", Buenos Aires, Waldhuter. p. 18.

Tilich, P. (2000). Christianity and the Encounter of the World Religions", citado por Navarro-Valls, R. y Palomino, R., “Estado y Religión”, Barcelona, Ariel, p. 324.

Vargas, V. “Ante los bárbaros”, Bogotá, Oveja Negra, 3ª edición, 1985.

Vásquez, C. A. (1986). "El poder presidencial en Colombia”, Suramérica Ltda., tercera edición. 